\title{
SINTESIS DAN UJI TOKSISITAS SENYAWA ANALOG PARA METIL KALKON
}

\author{
Elsaria Karsana ${ }^{1}$, Hilwan Yuda Teruna ${ }^{2}$, Adel Zamri²
}

1. Mahasiswa Program S1 Kimia FMIPA-Universitas Riau

2. Dosen Bidang Kimia Organik Jurusan Kimia FMIPA-Universitas Riau

Fakultas Matematika dan Ilmu Pengetahuan Alam, Univesitas Riau

Email: adel.zamri@lecturer.unri.ac.id

\begin{abstract}
ABSTRAK
Senyawa kalkon (E)-1,3-di-p-tolilprop-2-en-1-on telah berhasil disintesis dari 4'-metilasetofenon dan 4metilbenzaldehid melalui kondensasi Claisen-Schmidth menggunakan $\mathrm{NaOH}(3 \mathrm{~N})$ sebagai katalis dibawah iradiasi microwave menghasilkan rendemen sebesa 62,64\%. Senyawa yang dihasilkan diuji kemuniannya dengan KLT, uji titik leleh dan analisis HPLC serta dikarakteisasi strukturnya berdasarkan interpretasi data spektroskopi UV, FTIR, ${ }^{1} \mathrm{H}-\mathrm{NMR}$ dan MS. Uji toksisitas senyawa kalkon ini menggunakan metode Brine Shrimp Lethality Test (BSLT) terhadap larva Artemia salina Leach. Nilai LC L0 $_{50}$ untuk senyawa(E)-1,3-di-p-tolilprop-2-en-1-on adalah 7,656 $\mu \mathrm{g} / \mathrm{mL}$. Senyawa analog kalkon tersebut positif berpotensi sebagai antikanker.
\end{abstract}

Kata Kunci: kalkon, microwave, toksisitas

\section{PENDAHULUAN}

Senyawa flavonoid merupakan salah satu kelompok senyawa hasil alam yang banyak terdapat pada tanaman dan telah banyak dibuktikan mempunyai aktivitas fisiologis sebagai obat. Penelitian farmakologi terhadap senyawa flavonoid menunjukkan bahwa beberapa senyawa golongan ini memperlihatkan aktivitas yang menguntungkan seperti efek anti hepatotoksik, diuretik, dan anti tumor. Senyawa flavonoid di alam merupakan turunan kalkon melalui mekanisme biosintesis jalur shikimat dan jalur asetat-malonat. Kalkon juga merupakan salah satu anggota flavonoid yang mempunyai aktivitas biologis yang beragam dan merupakan intermediet untuk mensintesis senyawa flavonoid lainnya (Rahman, 2011).

Aktivitas biologis kalkon dipengaruhi oleh gugus karbonil $\alpha, \beta$-tak jenuh dan subtituen yang terikat pada kedua cincin aromatik (Kamble et al., 2011). Oleh karena itu, variasi subtituen pada kedua cincin aromatik akan menghasilkan kalkon dengan struktur yang beragam. Kalkon dengan variasi struktur yang luas hanya dapat diperoleh melalui sintesis secara kombinatorial.

Secara umum, senyawa kalkon dapat dibuat melalui kondensasi suatu aldehid aromatik dengan suatu keton aromatik baik dalam suasana asam maupun basa. Metode ini lebih dikenal dengan reaksi kondensasi aldol dan yang paling banyak digunakan adalah kondensasi ClaisenSchmidt (Jayapal et al., 2010). Reaksi kondensasi aldol dapat dilakukan dengan menggunakan katalis. Katalis yang digunakan bisa berupa asam maupun basa. Katalis asam yang biasa digunakan dalam reaksi kondensasi aldol antara lain $\mathrm{HCl}$ (Jayapal et al., 2010), SOCl2 (Jayapal and Sreedhar, 2011), H2SO4 dan zeolit (Kakati and Sarma, 2011). Sedangkan katalis basa yang biasa digunakan adalah $\mathrm{NaOH}$ (Choudhary and Juyal, 2011) dan KOH (Tiwari et al., 2010). Pada penelitian ini dilakukan sintesis satu molekul kalkon menggunakan bahan baku senyawa 4'-metilasetofenon dan 4metilbenzaldehid dengan metode ClaisenSchmidt.

\section{METODOLOGI PENELITIAN}

\section{Alat dan Bahan}

Alat-alat yang akan digunakan dalam penelitian ini adalah microwave Samsung ME109F, alat pengukur titik leleh Fisher Johns (SMP 11-Stuart ${ }^{\circledR}$ ), lampu 254/366 nm (Camag®), HPLC (Shimadzu LC Solution jenis kolom Shim-pack VP-ODS dengan panjang dan diameternya yaitu

150x4,6 mm), spektrofotometer UV (Genesys 10SUV-VIS v4.002 2L9N175013), 
spektrofotometer FTIR (Shimadzu, IR Prestige21), spektroskopi ${ }^{1} \mathrm{H}-\mathrm{NMR}$ (Agilent $500 \mathrm{mHz}$ ), spektroskopi Massa (MS Waters LCT premier XE mode positif), peralatan sintesis dan uji toksisitas yang umum digunakan di Laboratorium Sintesis Organik.

Bahan-bahan yang digunakan dalam penelitian ini adalah: 4'-metilasetofenon (Merck), 4-metil benzaldehid (Merck), Natrium hidroksida, asam klorida, plat KLT $\mathrm{GF}_{254}$, akuades, indikator universal, telur udang (Artemia salina Leach), air laut, metanol, etilasetat, n-heksana, diklorometan, etanol absolut, kloroform dan dimetilsulfoksida (DMSO).

\section{Sintesis senyawa kalkon}

Sebanyak 5 mmol 4'-metil asetofenon ditempatkan dalam wadah Erlenmeyer $125 \mathrm{~mL}$, kemudian ditambahkan $5 \mathrm{~mL}$ larutan natrium hidroksida 3N. Setelah itu, sebanyak $5 \mathrm{mmol} 4-$ metilbenzaldehid dan $5 \mathrm{~mL}$ etanol absolut ditambahkan ke dalam Erlenmeyer. Campuran ini diiradiasi microwave selama 7 menit dengan daya 180 watt. Reaksi dipantau melalui uji KLT setiap 1 menit. Setelah itu, sebanyak $15 \mathrm{~mL}$ akuades dingin ditambahkan kedalam campuran dan $\mathrm{pH}$ campuran dinetralkan dengan menambahkan tetes demi tetes asam klorida $3 \mathrm{~N}$, $\mathrm{pH}$ diukur menggunakan indikator universal. Kemudian campuran dibiarkan dalam lemari pendingin agar terbentuk endapan yang maksimal. Endapan yang terbentuk disaring dengan menggunakan corong buchner, dicuci dengan akuades dan n-heksana dingin, kemudian divakum hingga kering. Endapan tersebut kemudian direkristalisasi dengan etanol. Produk yang diperoleh diuji kemurniannya dengan uji KLT, titik leleh dan analisis HPLC. Jika senyawa yang didapat telah murni maka dilakukan karakterisasi struktur menggunakan spektroskopi UV, FTIR, ${ }^{1} \mathrm{H}-\mathrm{NMR}$ dan MS .

Uji toksisitas dengan metode brine shrimp lethality test (BSLT)

Sampel sebanyak $2 \mathrm{mg}$ dilarutkan dalam 2 $\mathrm{mL}$ metanol (larutan induk, konsentrasi 1000 $\mu \mathrm{g} / \mathrm{mL}$ ), kemudian dari larutan induk dibuat konsentrasi yang berbeda $100 \mu \mathrm{g} / \mathrm{mL}, 10 \mu \mathrm{g} / \mathrm{mL}$ dan $1 \mu \mathrm{g} / \mathrm{mL}$ dengan cara pengenceran bertingkat. Kemudian disiapkan vial $5 \mathrm{~mL}$ yang sudah dikalibrasi untuk masing-masing konsentrasi. Sampel dipipet kedalam masingmasing vial sebanyak $0,5 \mathrm{~mL}$, lalu pelarut diuapkan hingga mengering. Selanjutnya, kedalam masing-masing vial ditambahkan $50 \mu \mathrm{L}$ DMSO dan air laut sedikit. Sebanyak 10 ekor larva udang yang sudah disiapkan dimasukkan kedalam vial tersebut dan ditambah air laut hingga batas kalibrasi $5 \mathrm{~mL}$. Tingkat toksisitas diukur dengan cara menghitung jumlah larva udang yang masih hidup dalam selang waktu 24 jam. Pengujian dilakukan sebanyak tiga kali pengulangan dengan perlakuan yang sama untuk masing-masing konsentrasi. Data yang diperoleh dianalisis untuk menentukan nilai $\mathrm{LC}_{50}$ dengan metode kurva menggunakan tabel analisis probit.

\section{HASIL DAN PEMBAHASAN \\ Sintesis senyawa kalkon}

Sintesis yang telah dilakukan menghasilkan senyawa kalkon dengan rumus molekul $\mathrm{C}_{17} \mathrm{H}_{16} \mathrm{O}$ dan berat molekul sebesar 237,1284. Senyawa kalkon tersebut berupa kristal berwarna putih kekuningan. Sifat fisik dari senyawa kalkon yang dihasilkan dapat dilihat pada Tabel 1.

Tabel 1. Sifat fisika dari senyawa kalkon $\left(\mathrm{EC}_{3}\right)$

\begin{tabular}{cccccc}
\hline Senyawa & $\begin{array}{c}\text { Rumus } \\
\text { molekul }\end{array}$ & Berat molekul & Warna & Rendemen $(\%)$ & Ttik leleh $\left({ }^{\circ} \mathrm{C}\right)$ \\
\hline Kalkon & $\mathrm{C}_{17} \mathrm{H}_{16} \mathrm{O}$ & 237,1284 & $\begin{array}{c}\text { putih } \\
\text { kekuningan }\end{array}$ & $62,64 \%$ & $127-128$ \\
\hline
\end{tabular}

Senyawa kalkon disintesis melalui reaksi kondensasi aldol dari senyawa awal 4'metilasetofenon dan 4-metilbenzaldehid. Reaksi dilakukan menggunakan irradiasi microwave dan penambahan $\mathrm{NaOH}$ sebagai katalis. Senyawa kalkon yang diperoleh dimurnikan 
dengan rekristalisasi. Senyawa kalkon berupa kristal putih kekuningan dengan berat sebesar $0,7392 \mathrm{~g}$ dan rendemen yang dihasilkan sebesar $62,64 \%$.<smiles>Cc1ccc(C=CC(=O)c2ccc(C)cc2)cc1</smiles>

Tabel 2. Interpretasi data ${ }^{1} \mathrm{H}-\mathrm{NMR}$ senyawa kalkon

\begin{tabular}{cc}
\hline $\begin{array}{c}\text { Nomor } \\
\text { Atom }\end{array}$ & $\begin{array}{c}\text { Senyawa EC3 } \\
\boldsymbol{\delta} \mathbf{H}(\mathbf{p p m})\end{array}$ \\
\hline 1 & - \\
2 & $7,55(d, 2 \mathrm{H}, J=8,0)$ \\
3 & $7,23(d, 2 \mathrm{H}, J=7,9)$ \\
4 & - \\
5 & $7,23(d, 2 \mathrm{H}, J=7,9)$ \\
6 & $7,55(d, 2 \mathrm{H}, J=8,0)$ \\
7 & $2,39(\mathrm{~s}, 3 \mathrm{H})$ \\
$\mathrm{C}_{\alpha}$ & $7,50(d, 1 \mathrm{H} \alpha, J \mathrm{H} \alpha=15,65 \mathrm{~Hz})$ \\
$\mathrm{C}_{\beta}$ & $7,79\left(d, 1 \mathrm{H}_{\beta}, J \mathrm{H}_{\beta}=15,65 \mathrm{~Hz}\right)$ \\
$1^{\prime}$ & - \\
$2^{\prime}$ & $7,96(d, 2 \mathrm{H}, J=8,05 \mathrm{~Hz})$ \\
$3^{\prime}$ & $7,30(d, 2 \mathrm{H}, J=7,9 \mathrm{~Hz})$ \\
$4^{\prime}$, & - \\
$5^{\prime}$ & $7,30(d, 2 \mathrm{H}, J=7,9 \mathrm{~Hz})$ \\
$6^{\prime}$ & $7,96(d, 2 \mathrm{H}, J=8,05 \mathrm{~Hz})$ \\
$7^{\prime}$ & $2,44(s, 3 \mathrm{H})$ \\
\hline
\end{tabular}

Analisis kemurnian senyawa kalkon dilakukan menggunakan KLT, titik leleh, dan HPLC. Analisis kemurnian dengan KLT dilakukan menggunakan eluen yang bervariasi dan perbandingan yang berbeda. Senyawa kalkon menunjukkan satu noda pada plat KLT. Noda pada KLT diamati dengan bantuan lampu UV ( $\lambda 254 \mathrm{~nm}$ dan $366 \mathrm{~nm}$ ). Analisis kemurnian dengan titik leleh menunjukkan bahwa senyawa kalkon tersebut memiliki range titik leleh sebesar $1^{\circ} \mathrm{C}$. Analisis kemurnian senyawa kalkon menggunakan HPLC dilakukan pada panjang gelombang $243 \mathrm{~nm}$ dan $324 \mathrm{~nm}$ menunjukkan satu puncak dominan pada $\mathrm{t}_{\mathrm{R}}=15,67$ menit. Berdasarkan data analisis kemurnian tersebut menunjukkan bahwa senyawa kalkon telah murni. Struktur senyawa kalkon yang telah murni kemudian dikarakterisasi menggunakan spektroskopi UV,
IR, ${ }^{1} \mathrm{H}-\mathrm{NMR}$ dan MS. Spektrum UV senyawa kalkon memperlihatkan adanya serapan maksimum pada $\lambda 208,230$, dan $321 \mathrm{~nm}$. Berdasarkan nilai serapan maksimum senyawa tersebut menunjukkan adanya ikatan rangkap terkonjugasi.

Spektrum IR dari senyawa kalkon hasil sintesis memperlihatkan adanya serapan yang khas pada bilangan gelombang $2998 \mathrm{~cm}^{-1}$ yang menunjukkan adanya gugus $\mathrm{C}-\mathrm{H}$ aromatik, pada

bilangan gelombang $1380 \mathrm{~cm}^{-1}$ yang menunjukkan adanya gugus $\mathrm{C}=\mathrm{C}$ terkonjugasi, pada $2859 \mathrm{~cm}^{-1}$ menunjukkan ikatan antara $\mathrm{Ar}-$ $\mathrm{CH}_{3}$ dan pada bilangan gelombang $1607 \mathrm{~cm}^{-1}$ menunjukkan adanya gugus karbonil $(\mathrm{C}=\mathrm{O})$. Spektrum ${ }^{1} \mathrm{H}$ NMR senyawa analog kalkon hasil sintesis menunjukkan pergeseran kimia pada $\delta=$ $2,44(\mathrm{~s}, \quad 3 \mathrm{H}) \quad$ dan $2,39(\mathrm{~s}, \quad 3 \mathrm{H}) \quad$ yang memperlihatkan adanya gugus metil $\left(\mathrm{CH}_{3}\right)$. Pergeseran kimia yang khas pada $7,79\left(\mathrm{~d}, 1 \mathrm{H}_{\beta}\right.$, $\left.\mathrm{JH}_{\beta}=15,65 \mathrm{~Hz}\right)$ dan 7,50 (d, $1 \mathrm{H} \alpha, \mathrm{JH} \alpha=15,65$ $\mathrm{Hz})$ memperlihatkan proton $\mathrm{H}$ pada $\mathrm{C}-\beta$ dan $\mathrm{C}$ $\alpha$. Berdasarkan harga tetapan kopling (J) pada C$\beta$ dan $\mathrm{C}-\alpha$ dapat diperkirakan bahwa proton pada ikatan rangkap ini mempunyai konfigurasi trans.

Spektrum MS senyawa kalkon hasil sintesis menunjukkan puncak ion molekul yang sesuai dengan perhitungan. Spektrum MS senyawa $\left(\mathrm{EC}_{3}\right)$ menunjukkan adanya puncak ion molekul yang dihitung sebagai $\mathrm{C}_{17} \mathrm{H}_{17} \mathrm{O}(\mathrm{M}+\mathrm{H})^{+}$pada 237, 1279 sedangkan yang ditemukan adalah 237,1284 . Berdasarkan puncak ion molekul yang dihasilkan spektrum MS dan yang dihitung secara teoritis terlihat selisih nilai yang dihasilkan sangat kecil yaitu 0,0006 . Hal ini menunjukkan senyawa hasil sintesis telah murni dan mempunyai struktur sesuai dengan yang diharapkan.

\section{Uji toksisitas}

Senyawa (E)-1,3-di-p-tolilprop- 2-en-1-on dengan nilai $\mathrm{LC}_{50} 7,656 \mu \mathrm{g} / \mathrm{mL}$ menunjukkan tingkat toksisitas yang cukup baik. Hal ini dikarenakan adanya gugus metil yang terletak pada posisi para sehingga meningkatkan aktivitas toksisitas senyawa. Hasil uji toksisitas senyawa analog kalkon yang diperoleh dapat dikatakan positif berpotensi sebagai senyawa 
antikanker terbukti dari sifat toksisitasnya dengan nilai $\mathrm{LC}_{50}<200 \mu \mathrm{g} / \mathrm{mL}$.

\section{KESIMPULAN}

Berdasarkan hasil penelitian yang telah dilakukan, maka dapat diambil kesimpulan bahwa senyawa kalkon $\left(\mathrm{EC}_{3}\right)$ diperoleh melalui reaksi kondensasi aldol Claisen-Schmidt menggunakan katalis basa $(\mathrm{NaOH})$ dibawah iradiasi microwave. Rendemen yang dihasilkan yaitu $62,64 \%$. Hasil karakterisasi menggunakan spektroskopi UV, IR, ${ }_{1} \mathrm{H}-\mathrm{NMR}$ dan MS menunjukkan bahwa senyawa yang diperoleh dari hasil penelitian merupakan senyawa kalkon dengan struktur yang diharapkan. Melalui hasil uji toksisitas yang didapat terlihat senyawa berpotensi aktif sebagai antikanker karena mempunyai $\mathrm{LC}_{50}$ sebesar $7,656 \mu \mathrm{g} / \mathrm{mL}$. Agar diperoleh hasil yang lebih baik pada penelitianpenelitian selanjutnya, maka penulis menyarankan perlu dilakukan sintesis lebih lanjut terhadap kalkon yang memiliki gugus metil dengan memvariasikan subtituen pada bahan baku yang digunakan serta perlu dilakukan pengujian sitotoksik untuk lebih mengetahui potensi senyawa kalkon terhadap antikanker

\section{DAFTAR PUSTAKA}

Choudhary, A.N. and Juyal, V. 2011. Synthesis of Chalcone and their Derivates as Antimicrobial Agents. International Journal of Pharmacy and Pharmaceutical Sciences. 3(3): 125-128.
Jayapal, M.R. and Sreedhar, N.Y. 2011. Synthesis and Characterization of 2,5Dihydroxy Substituted Chalcones Using SOCl2/EtOH. International Journal of Pharmacy and Pharmaceutical Sciences. 3(1): 127-129.

Jayapal, M.R., Prasad, K.S., and Sreedhar, N.Y. 2010. Synthesis and Characterization of 2,6-Dihydroxy Substituted Chalcones Using PEG-400 As a Recyclable Solvent. Journal of Pharmaceutical Science and Research. 2(8): 450-458.

Kakati, D., and Sarma ,J.C. 2011. Microwave Assisted Solvent Free Synthesis of 1,3Diphenylpropenones. Chemistry Central Journal. 5(8): 1-5.

Kamble, V.M., Hatnapure, G.D., Keche, A.P., Biradjar, S., Patil, S.G., Tale, R.H., Rodge, A.H., Turkar, S.S. and Gour, K. 2011. Synthesis and Biological Evaluation of a Novel Series of Methoxylatedchalcone as Antioxidant and Anti-microbial Agents. Journal of Chemical and Pharmaceutical Research. 3(6): 639-648.

Rahman, M.A. 2011. Chalcone: A Valuable Insight into the Recent Advances and Potential Pharmacological Activities. Chemical Sciences Journal. 29: 1-16.

Tiwari, B., Pratapwar, A.S., Tapas, A.R., Butle, S.R., and Vatkar, B.S. 2010. Synthesis and Antimicrobial Activity of Some Chalcone Derivatives. International Journal of ChemTech Research. 1(2): 499-503. 